PUBLIK: Jurnal Manajemen Sumber Daya Manusia, Administrasi dan Pelayanan Publik Sekolah Tinggi Ilmu Administrasi Bina Taruna Gorontalo Volume VI Nomor 2 Desember 2019

\title{
IMPLEMENTASI KEBIJAKAN PENCEGAHAN PEMBERANTASAN PENYALAHGUNAAN DAN PEREDARAN GELAP NARKOTIKA (P4GN) OLEH BADAN NARKOTIKA NASIONAL KOTA GORONTALO
}

\author{
Misbahudin Djaba' ${ }^{1}$ \& Ellys Rachman ${ }^{2}$ \\ STIA Bina Taruna Gorontalo \\ $\underline{\text { misbahudindjaba014@gmail.com }}$ \& ellysrachman12@gmail.com ${ }^{2}$
}

\begin{abstract}
ABSTRAK
Penelitian ini bertujuan untuk mengetahui Kebijakan Pencegahan, Penyalahgunaan dan Penyebaran Gelap Narkotika (P4GN) di Badan Narkotika Nasional (BNN) Kota Gorontalo. Metode penelitian menggunakan jenis deskriptif dengan pendekatan kualitatif. Teknik pengumpulan data dengan observasi dan entri data sekunder, wawancara mendalam ke lebih banyak informan, dan dokumentasi.

Hasil penelitian menyimpulkan bahwa: kurangnya kuantitas Pelaksana (Petugas) yang dimiliki oleh tiga area yang secara fungsional mengimplementasikan P4GN. Lebih baik daripada Sektor Pencegahan dan Pemberdayaan Masyarakat (P2M), Sektor rehabilitasi, dan Sektor Pemberantasan. Fasilitas kurang atau tidak memadai. Ini bisa dilihat pada proposisi fasilitas yang masih kurang memadai, seperti: jenis atau miniatur narkotika, alat kesehatan untuk klinik rehabilitasi, senjata, alat komunikasi, dan kendaraan operasional. Komunikasi Badan Narkotika Nasional (BNN) Kota Gorontalo dengan organisasi atau masyarakat mendukung implementasi P4GN yang masih kurang intensif. Hal ini terlihat dari komunikasi yang dibangun oleh Sektor P2M telah mencapai 70\%, Sektor Rehabilitasi hanya bermitra dengan LSM SORGA dalam pelaksanaan rehabilitasi, dan Sektor Pemberantasan masih kurang maksimal dalam memilih informasi dari masyarakat.

Disarankan, kepada BNN Kota Gorontalo agar dapat meningkatkan kuantitas pelaksana (petugas), seperti: petugas penyuluh, dokter dan perawat medis, dan kepolisian. Diharapkan BNN Kota Gorontalo menyediakan fasilitas, berupa: miniatur narkotika, alat kesehatan, senjata, alat komunikasi, dan kendaraan operasional serta terus menjalin komunikasi dengan unsur-unsur yang dapat membantu implementasi P4GN.
\end{abstract}

Kata Kunci: Implementasi; Kebijakan; P4GN 


\section{PENDAHULUAN}

Di tengah berjalannya pembangunan manusia yang sesuai dengan amanah nawacita pemerintah Indonesia, permasalahan-permasalahan sosial terus berdatangan dan menghambat berjalannya pembangunan. Salah satu permasalahan tersebut adalah penyalahgunaan Narkotika. Penyalahgunaan dan peredaran gelap Narkotika merupakan permasalahan kolektif (collective problem), baik bagi Lembaga yang ditunjuk pemerintah untuk bertanggung jawab, mahasiswa sebagai kaum intelektual, dan juga segenap masyarakat. Narkotika pada masa ini sudah merambah ke setiap sudut kehidupan masyarakat Indonesia. Mulai dari anak-anak sampai orang dewasa, dari pekerja sampai para pelajar, dan bahkan para publik figur dan aparatur negara, tidak luput dari penyalahgunaan Narkotika. Sebagai salah satu masalah sosial ditatanan nasional, diberlakukanlah Undang-Undang Nomor 35 Tahun 2009 Tentang Narkotika sebagai dasar hukum. Undang-Undang ini, menjadi transformasi kesekian kalinya dari kebijakan-kebijakan dalam bentuk regulasi yang pernah disahkan oleh negara.

Dalam Undang-Undang Nomor 35 Tahun 2009 pada Pasal 1 dijelaskan: Narkotika adalah zat atau obat yang berasal dari tanaman atau bukan tanaman, baik sintetis maupun semi sintetis, yang dapat menyebabkan penurunan atau perubahan kesadaran, hilangnya rasa, mengurangi sampai menghilangkan rasa nyeri, dan dapat menimbulkan ketergantungan, yang dibedakan ke dalam golongangolongan terlampir dalam UndangUndang ini. Adapun golongangolongan yang dilampirkan dalam Undang-Undang tersebut, ada tiga golongan. Golongan I ada 65 jenis, Golongan II ada 86 Jenis, dan Golongan III ada 14 jenis. Untuk menangani masalah Narkotika yang semakin meluas, dibentuklah Badan Narkotika Nasional, sebagaimana yang termaktub dalam Undang-Undang nomor 35 Tahun 2009 Pasal 64 ayat 1 dan 2, menyebutkan: Dalam Rangka pencegahan dan pemberantasan penyalahgunaan dan peredaran gelap Narkotika dan precursor Narkotika, dengan Undang-Undang ini dibentuk Badan Narkotika Nasional, yang selanjutnya disingkat BNN. BNN sebagaimana dimaksud pada ayat (1) merupakan lembaga pemerintah nonkementerian yang berkedudukan di bawah Presiden dan bertanggung jawab kepada Presiden. Pembentukan Badan Narkotika Nasional yang sebelumnya dijelaskan dalam UndangUndang Nomor 35 tahun 2009, didasari oleh Peraturan Presiden (Perpres) Nomor 23 Tahun 2010 Tentang Badan Narkotika Nasional, yang mengatur arah gerak dari BNN khususnya tugas pokok, dan fungsi 
dari BNN untuk menjalankan kebijakan nasional Pencegahan, Pemberantasan Penyalahgunaan dan Peredaran Gelap Narkotika (P4GN). Untuk mempermudah melaksanakan kebijakan nasional mengenai P4GN, Badan Narkotika Nasional yang berada di pusat, dibantu oleh Instansi Vertikal, yaitu BNN Provinsi (BNNP) dan BNN Kota/Kabupaten (BNNK). Keduanya adalah pelaksana tugas BNN pusat di daerah. Badan Narkotika Nasional Kota Gorontalo yang kemudian disingkat BNN Kota Gorontalo, menjadi salah satu instansi vertikal. Sebagai pelaksana tugas kebijakan nasional P4GN di Kota Gorontalo. Peranan dari BNN Kota Gorontalo terus disorot setiap harinya, mengingat Kota Gorontalo saat ini terus dibayang-bayangi oleh penyalahgunaan dan peredaran gelap Narkotika yang semakin meluas. Dari data rehabilitasi yang dimiliki oleh Badan Narkotika Nasional Provinsi Gorontalo, ada sekitar 815 penyalahgunaa yang berhasil melewati rehabilitasi medis, yang dirangkum dari tahun 2015 sampai tahun 2018. Selanjutnya, data yang dinukil dari hasil liputan Gorontalo Post dari Res Narkotika Polres Gorontalo Kota, pada Tahun 2016 terdapat 23 kasus pengedaran Narkotika. Selain itu track record kasus penyalahgunaan Narkotika di Kota Gorontalo, terhitung dari Januari-November 2018. Terdapat tiga belas kasus, yang terdiri dari penyalahgunaan sampai peredaran gelap Narkotika. Dari tiga belas kasus yang didapatkan ada 12 kasus tentang penyalahgunaan dan peredaran gelap Narkotika jenis sabu-sabu (Narkotika Golongan I), serta satu kasus lagi tentang peredaran narkotika jenis Tembakau Gorilla (Narkotika Golongan I). Keseluruhan data kasus tersebut didapatkan oleh peneliti lewat penelusuran pemberitaan di sejumlah media, baik lokal maupun nasional. Di antaranya: detik.com, kompas.com, liputan6.com, hargo.co.id, dan radargorontalo.com.

Permasalahan Narkotika di Kota Gorontalo masuk dalam jenjang yang semakin serius. Hal ini berdasar dari observasi peneliti di sekitar lingkungan peneliti, para korban penyalahgunaan dapat diklasifikasikan menjadi dua bagian, menurut pemakaian. Bagian pertama adalah anak-anak (usia Sekolah Dasar (SD) sampai Sekolah Menengah Pertama (SMP)), mayoritas dari kategori pertama ini menjadi pengguna Zat Adiktif, seperti Hbone (lem plastik) yang mengandung Lysergic Acid Diethyilamide (LSD) dengan dampak menimbulkan ketergantungan dan kerusakan fungsi otak. Bagian kedua ditempati oleh para remaja (usia Sekolah Lanjutan Tingkat Atas (SLTA) sampai Mahasiswa), mereka menjadi pengguna Bulan (minuman oplosan hasil campuran Obat Batuk Komix yang memiliki 
PUBLIK: Jurnal Manajemen Sumber Daya Manusia, Administrasi dan Pelayanan Publik Sekolah Tinggi Ilmu Administrasi Bina Taruna Gorontalo Volume VI Nomor 2 Desember 2019

kandungan dextromethorphan dengan minuman energi/soda), Katapel/Kapuka (Pil Y) yang menjadi salah satu obat terlarang, Kristal (Crystal/Meth golongan obat bius), dan Mushroom (Psilocybin/magicmushroom) yang masuk dalam Narkotika Golongan I.

Tugas dari BNN untuk menyusun dan melaksanakan kebijakan nasional dalam hal P4GN yang kini diemban oleh BNN Kota Gorontalo. Dengan tiga bidang fungsional yang dimiliki BNN Kota Gorontalo, di antaranya Bidang Pencegahan dan Pemberdayan Masyarakat $\quad(\mathrm{P} 2 \mathrm{M}), \quad$ Bidang Rehabilitasi dan Bidang Pemberantasan. Secara umum menjalankan tugas, seperti: sosialisasi secara merata khususnya pada kalangan pelajar, sebagai bentuk edukasi tentang bahaya Narkotika; pemberantasan dengan melakukan penangkapan, penyitaan serta meretas dan memutus jaringan Narkotika yang ada Kota Gorontalo; memaksimalkan rehabilitasi medis dan sosial dengan koordinasi yang berkesinambungan dengan Lembaga Medis dan organisasi lain yang dapat membantu dalam proses rehabilitasi. Namun saat ini, BNN Kota Gorontalo terlihat belum maksimal dalam menjalankan program P4GN. Permasalahan ini tercipta karena ada beberapa hal yang menjadi penghambat.
Pertama, masih kurang maksimalnya Implementor dalam mengawal pengimplementasian kebijakan. Hal ini dilihat dari segi kuantitas petugas yang dimiliki oleh BNN Kota Gorontalo, dalam tiga bidang fungsional. Seperti Bidang Pencegahan dan Pemberdayaan Masyarakat (P2M), yang menjalankan tugas utama penyuluhan, hanya memiliki dua orang penyuluh. Bidang Rehabilitasi yang menjalankan rehabilitasi medis, masih kekurangan petugas kesehatan. Serta bidang pemberantasan yang masih kekurangan petugas untuk melakukan operasi atau razia. Kedua, masih kurangnya fasilitas atau sarana prasarana yang menunjang kinerja dari BNN Kota Gorontalo, khususnya tiga bidang fungsional yang dimiliki oleh BNN Kota Gorontalo. Fasilitas yang kurang memadai tersebut, seperti: miniatur jenis narkotika yang digunakan dalam sosialisasi/penyuluhan; perangkat medis; senjata api dan alat komunikasi untuk petugas pemberantasan; serta kendaraan operasional. Ketiga, masih kurang intensifnya komunikasi yang dibangun oleh BNN Kota Gorontalo, dengan beberapa unsur (Organisasi Mahasiswa, Lembaga Swadaya Masyarakat dan Non Governmental Organization) yang dapat membantu BNN Kota Gorontalo dalam melaksanakan tugas. Hal ini terlihat dari masing-masing bidang fungsional 
di BNNK Gorontalo, seperti; Bidnag P2M yang saat ini baru dapat merangkul 150 orang yang terdiri dari penggiat dan relawan, sementara untuk para siswa belum terjaring dalam program relawan dan penggiat; Bidang Rehabilitasi yang baru dapat mendukung LRKM (Lembaga Rehabilitasi Komponen Masyarakat) LSM SORGA (Lembaga Swadaya Masyarakat Solidaritas Relawan Gorontalo) untuk menjadi wadah rehabilitasi sosial bagi penyalahguna, pasca menjalani rehabilitasi medis; dan Bidang Pemberantasan yang belum bisa menjaring informasi lebih luas lagi kepada masyarakatterkait tindak peredaran atau perdagangan Narkotika.

\section{PERMASALAHAN}

Berdasarkan uraian tersebut di atas, maka rumusan masalah dalam penelitianini adalah: "Bagaimana Implementasi Kebijakan Pencegahan, Pemberantasan Penyalahgunaan dan Peredaran Gelap Narkotika (P4GN) Oleh Badan Narkotika Nasional Kota Gorontalo?"

\section{TUJUAN DAN MANFAAT PENELITIAN}

\section{Tujuan Penelitian}

Tujuan penelitian ini, untuk memahami Implementasi Kebijakan Pencegahan, Pemberantasan Penyalahgunaan dan Peredaran Gelap
Narkotika (P4GN) oleh Badan Narkotika Nasional Kota Gorontalo.

\section{Manfaat Penelitian}

Selaras dengan tujuan penelitian yang akan dicapai, maka hasil dari penelitian ini diharapkan dapat memberikan manfaat baik secara teoritis maupun praktis.

Manfaat teoritis adalah sebagai kajian baru dalam pengembangan ilmu administrasi dan dapat pula dijadikan bahan perbandingan bagi penelitian lainnya.

Manfaat praktis dari penelitian ini diharapkan dapat menjadi bahan bagi BNN Kota Gorontalo dalam melakukan P4GN.

\section{METODE PENELITIAN}

Adapun yang menjadi objek penelitian dalam penulisan ini adalah di BNN Kota Gorontalo, dengan berbagai pertimbangan sebagai berikut: Lokasi penelitian berada pada tempat yang mudah dijangkau oleh peneliti; Memudahkan peneliti dalam melakukan studi secara mendalam terhadap masalah yang sedang diteliti, karena peneliti memahami kondisi sosial masyarakat setempat; Permasalahan tentang Implementasi P4GN yang diteliti, berada di organisasi tersebut. Penelitian ini menggunakan jenis penelitian deskriptif dengan pendekatan kualitatif 
PUBLIK: Jurnal Manajemen Sumber Daya Manusia, Administrasi dan Pelayanan Publik Sekolah Tinggi Ilmu Administrasi Bina Taruna Gorontalo Volume VI Nomor 2 Desember 2019

guna mengetahui dan meneliti bagaimana Implementasi P4GN (Pencegahan, Pemberantasan dan Peredaran Gelap Narkotika) oleh Badan Narkotika Nasional.

\section{Fokus Penelitian}

Penelitian mengenai Implementasi Kebijakan Pencegahan, Pemberantasan Penyalahgunaan dan Peredaran Gelap Narkotika (P4GN) Oleh Badan Narkotika Nasional Kota Gorontalo difokuskan pada:

\section{Implementor}

Yaitu petugas atau implementor yang melaksanakan tugas dalam P4GN oleh BNN Kota Gorontalo

\section{Fasilitas}

Yaitu sarana dan prasarana yang dibutuhkan oleh para petugas dalam rangka melaksanakan $\mathrm{P} 4 \mathrm{GN}$ oleh BNN Kota Gorontalo

\section{Komunikasi}

Yaitu pengiriman pesan dari komunikator kepada komunikan agar pelaksanaan P4GN oleh BNN Kota Gorontalo lebih efektif dan efisien.

\section{HASIL PENELITIAN DAN PEMBAHASAN}

Badan Narkotika Nasional Kota Gorontalo memegang tugas untuk menjalankan kebijakan nasional P4GN di Kota Gorontalo. Berikut adalah uraian pembahasan tentang Implementasi Kebijakan Pencegahan
Pemberantasan Penyalahgunaan dan Peredaran Gelap Narkotika (P4GN). Oleh Badan Narkotika Nasional Kota Gorontalo, dengan fokus penelitian: Implementor (Petugas BNN), Fasilitas, dan Komunikasi.

\section{Implementor}

Implementor atau petugas yang melakukan implementasi suatu kebijakanatau program. Sebagai sumber daya utama dan kunci dari implementasi, implement rmemegang peranan penting dalam proses tersebut. Maksimalnya kinerja dari implementr bergantung pada jumlah implementor yang dimiliki suatu organisasi.

Dalam penelitian ini implementor yang dimaksud adalah petugas dari BNNK Gorontalo yang melaksanakan tugas implementasi kebijakan nasional P4GN. Dalam implementasi P4GN oleh implementor (petugas) dari BNN Kota Gorontalo, implementor (petugas) terbagi dalam tiga bidang fungsional, yaitu: Bidang Pencegahan dan Pemberdayaan Masyarakat; Bidang Rehabilitasi; dan Bidang Pemberantasan. Berdasarkan hasil penelitian dan analisis peneliti, diketahui bahwa masih kurangya kinerja dari implementor. Hal ini terlihat dari kurangnya jumlah implementor (petugas), yang dimiliki oleh BNN Kota Gorontalo di segala bidang. Baik Bidang Pencegahan dan Pemberdayaan Masyarakat (P2M), Bidang Rehabilitasi dan Bidang 
Pemberantasan. Sehingga kinerja dari implementor tidak maksimal, mengingat para implementor melaksanakan tugas di wilayah Kota Gorontalo yang menjadi Ibu Kota Provinsi Gorontalo dan pusat administrasi dari Gorontalo. Sehingga dibutuhkan implementor dalam jumlah lebih, agar penanganan Narkotika di Kota Gorontalo dapat dilaksanakan secara maksimal.

\section{Fasilitas}

Fasilitas yang didefinisikan pelaksanaan fungsi. Fasilitas menjadi penunjang bagi para petugas saat implementasi suatu kebijakan, agar tujuan dari kebijakan dapat tercapai secara efektif dan efisien. Dalam penelitian ini, fasilitas yang dimaksud adalah ketersediaan sarana yang digunakan oleh petugas BNN Kota Gorontalo dalam menjalankan tugasnya. Dari hasil penelitian dan analisis yang dilakukan oleh peneliti, diketahui bahwa ketersediaan fasilitas di BNN Kota Gorontalo belum memadai. Hal ini terungkap dari kurangnya fasilitas di setiap bidang fungsional yang dimiliki oleh BNN Kota Gorontalo, dimulai dari: Bidang Pencegahan dan Pemberdayaan Masyarakat (P2M) yang masih kekurangan alat peraga atau miniature dari jenis narkotika untuk kepentingan penyuluhan; Bidang Rehabilitasi yang masih kekurangan fasilitas, dalam hal ini perangkat medis yang digunakan dalam klinik rehabilitasi medis; Bidang Pemberantasan yang masih kekurangan fasilitas dalam bentuk senjata api dan alat komunikasi yang digunakan dalam operasi penangkapan (pemberantasan).

\section{Komunikasi}

Komunikasi. Secara definitif komunikasi diartikan sebagai pengiriman dan penerimaan pesan atau berita antara dua orang atau lebih sehingga pesan yang dimaksud dapat dipahami. Melihat pengertian mengenai komunikasi, maka secara implisit komunikasi dapat diartikan sebagai suatu bentuk pertukaran informasi yang melibatkan informan dan komunikan sehingga keduanya saling terhubung dan memahami satu sama lain. Dalam lingkup organisasi, komunikasi menjadi bagian vital dari organisasi dalam mencapai tujuannya. Baik komunikasi secara internal dalam bentuk vertikal atau horizontal, atau komunikasi dengan lingkungan organisasi. Suatu komunikasi tercapai dapat dilihat dari kesemaan persepsi atau terjalinnya kerja sama, karena sudah memiliki pandangan yang sama terkait suatu tujuan yang ingin dicapai.

Dalam penelitian ini komunikasi yang dimaksud adalah komunikasi yang intensif antara pihak BNN Kota Gorontalo dengan Organisasi atau Komunitas yang dapat membantu tugas BNN Kota Gorontalo. Berdasarkan hasil penelitian dan 
PUBLIK: Jurnal Manajemen Sumber Daya Manusia, Administrasi dan Pelayanan Publik Sekolah Tinggi Ilmu Administrasi Bina Taruna Gorontalo Volume VI Nomor 2 Desember 2019

analisis yang dilakukan oleh peneliti, maka dapat diketahui bahwa komunikasi yang dibangun oleh BNN Kota Gorontalo dengan pihak luar (organisasi atau komunitas) belum terlalu intensif. Hal ini tampak dari beberapa kekurangan yang terlihat pada tiga bidang fungsional yang dimiliki BNN Kota Gorontalo, di antaranya: Bidang Pencegahan dan Pemberdayaan Masyarakat (P2M), yang saat ini komunikasi yang dibangun baru $70 \%$ dan hanya intensif dengan beberapa organisasi dan komunitas, sementara masih banyak organisasi dan komunitas yang belum terjangkau untuk dapat membantu tugas dari bidang tersebut, salah satunya siswa dan organisasi mahasiswa; Bidang Rehabilitasi, yang masih kurang intensifnya komunikasiyang dibangun dengan masyarakat, serta belum dapat menjangkau LSM atau Lembaga rehabilitasi lain, dimana saat ini hanya Lembaga Rehabilitasi Komponen Masyarakat (LRKM) Lembaga Swadaya Masyarakat (LSM) Solidaritas Relawan Gorontalo (SORGA) yang menjadi mitra satusatunya untuk melaksanakan rehabilitasi sosial dan pendampingan rehabilitasi medis bagi penyalahguna; Bidang Pemberantasan, yang selaras dengan masalah dari Bidang Rehabilitasi terkait penjaringan informasi dari masyarakat yang masih kurang, sehingga komunikasi yang kemudian dapat berwujud dalam bentuk kerja sama tidak terjalin dengan baik.

\section{SIMPULAN}

Berdasarkan hasil penelitian dan pembahasan sebelumnya, maka selanjutnya dilakukan penarikan kesimpulan sebagai berikut:

1. Implementor BNN Kota Gorontalo belum maksimal dalam mengimplementasikan kebijakan P4GN. Hal ini ini terlihat dari kurangnya jumlah implementor yang dimiliki oleh ketiga bidang yang secara fungsional mengimplementasikan P4GN. Baik dari Bidang Pencegahan dan Pemberdayaan Masyarakat (P2M), Bidang Rehabilitasi, dan BidangPemberantasan.

2. Fasilitas yang dimiliki oleh BNN Kota Gorontalo masih kurang atau belum memadai. Hal ini terlihat dari jumlah fasilitas yang masih belum memadai, seperti: alat peraga atauminatur jenis Narkotika, perangkat medis untuk klinik rehabilitasi, senjata api, alatkomunikasi, dan mobil operasional.

3. Komunikasi dari BNN Kota Gorontalo dengan Organisasi atau komunitas yang mendukung tugas dari BNN Kota Gorontalo masih kurang intensif. Hal ini terlihat dari komunikasi yang dibangun oleh ketiga bidang di BNN Kota Gorontalo, seperti: Bidang Pencegahan dan Pemberdayaan 
Masyarakat (P2M) yang saat ini komunikasinya baru 70\%; Bidang Rehabilitasi yang saat ini bermitra dengan LSM SORGA sebagai satusatunyaLembaga Rehabilitasi Komponen Masyarakat (LRKM) yang menjadi lembaga rehabilitasi sosial dan pendamping penyalah guna saat menjalani rehabilitasi medis; Bidang Pemberantasan yang masih kurang intensif dalam membangun komunikasi dengan masyarakat agar dapat menjaring informasi.

\section{SARAN}

Berdasarkan simpulan di atas, maka hal yang dapat disarankan adalah sebagai berikut:

1. Diharapkan adanya upaya dari pihak BNN Kota Gorontalo untuk mengajukan permohonan kepada Badan Narkotika Nasional Republik Indonesia dan Pemerintahan Daerah untuk menambahkan jumlah implementor yang bertugas melakukan implementasi P4GN Serta peningkatan upaya untuk terus menjaring Relawan dan Penggiat yang berasal dari Masyarakat, Aparatur SIpil Negara (ASN), Pegawai Swasta, dan para Pelajar atau Mahasiswa.

2. Diharapkan adanya upaya dari BNN Kota Gorontalo untuk menyediakan fasilitas yang dapat menunjang fungsi dari setiap bidang yang berperan dalam Implementasi Kebijakan P4GN. Seperti: alat peraga atau miniatur jenis narkotika untuk Bidang P2M
(Pencegahan dan Pemberdayaan); fasilitas medis di klinik rehabilitasi medis, untuk Bidang Rehabilitasi; alat komunikasidan senjata api, bagi Bidang Pemberantasan untuk menunjang tugas operasi pemberantasan; serta fasilitas mobil operasional untuk mempermudah mobilisasi para petugas.

3. Diharapkan adanya upaya dari pihak BNN Kota Gorontalo untuk lebih meningkatkan intensifitas komunikasi dengan unsur dan stakeholder yang dapat membantu tugas BNN Kota Gorontalo dalam implementasi kebijakan P4GN. Seperti: Organisasi Mahasiswa, Lembaga Swadaya Masyarakat (LSM), Non Governmental Organization, Organisasi Masyarakat, Pihak Kepolisian, dan Pihak rumah sakit yang menyelenggarakan rehabilitasi medis.

\section{DAFTAR PUSTAKA}

Agustino, Leo. 2008. Dasar-Dasar Kebijakan Publik. Bandung: Alfabeta.

Anggara, Sahya. 2014. Kebijakan Publik. Bandung: CV Pustaka Setia.

Badan Narkotika Nasional Republik Indonesia. 2015. Press Release Akhir Tahun2015. Jakarta: HUMAS (BNN) Badan Narkotika Nasional

Republik Indonesia.

Badan Narkotika Nasional Republik Indonesia. 2016. Laporan Kinerja Badan Narkotika 
PUBLIK: Jurnal Manajemen Sumber Daya Manusia, Administrasi dan Pelayanan Publik Sekolah Tinggi Ilmu Administrasi Bina Taruna Gorontalo Volume VI Nomor 2 Desember 2019

Nasional 2016. Jakarta: Badan

Narkotika Nasional Republik Indonesia.

Fajar, Marhaeni. 2009. Ilmu

Komunikasi Teori \& amp; Praktek (Edisi Pertama).

Yogyakarta: Graha Ilmu.

Fischer, Frank. Et all. Handbook of

Public Policy Analysis (Theory,

Politics, and Methods).

Dialihbahasakan oleh Imam

Baihaqi. 2014. Handbook

Analisis Kebijakan Publik

(Teori, Politik dan Metode).

Bandung: Nusa Media.

Frisdiantara, Christea. 2013. Pengaruh

Dimensi Pelayanan dan Dimensi

Fasilitas Terhadap Kepuasan

Mahasiswa Pada Universitas

Kanjuruhan Malang. Malang:

Universitas Kanjuruhan Malang.

Ibrahim, Amin. 2009. Pokok-Pokok

Administrasi Publik dan

Implementasinya. Bandung: PT

Refika Aditama

Iskandar, Anang. 2015. Jalan Lurus

(Penanganan Penyalah guna

Narkotika Dalam Konstruksi

Hukum Positif). Karawang: Viva

Tanpas

Kesehatan, Kementerian Republik

Indonesia. 2014. Buletin Jendela

Data dan Informasi Kesehatan.

Jakarta: Kementerian Kesehatan

Republik Indonesia.

Makmur. 2009. Patologi Serta

Terapinya Dalam Ilmu

Administrasi dan Organisasi.

Bandung: PT Refika Aditama
Rusli, Budiman. 2013. Kebijakan Publik Membangun Pelayanan Publik Yang Responsif. Bandung: Hakim Publishing Siagian, P. Sondang. 2014. FIlsafat Administrasi. Jakarta: PT Bumi Aksara

Siagian, P. Sondang. 2009. Administrasi Pembangunan (Konsep, Dimensi, dan Starteginya). Jakarta: PT Bumi Aksara

Subarsono, AG. 2013. Analisis Kebijakan Publik (Konsep, Teori dan Aplikasi). Yogyakarta: Pustaka Pelajar

Sugiyono. 2013. Metode Penelitian Administrasi. Bandung: Alfabeta.

Sugandi, Yogi Suprayogi. 2011. Administrasi Publik Konsep dan Perkembangan Ilmu di Indonesia. Yogyakarta: Graha Ilmu

Suharsaputra, Uhar. 2012. Metode Penelitian Kuantitatif, Kualitatif, dan Tindakan. Bandung: PT Refika Aditama

Suryana. 2010. Buku Ajar Perkuliahan Metodologi Penelitian Model PraktisPenelitian Kuantitatif dan Kualitatif. Bandung: Universitas Pendidikan Indonesia

Suharno. 2013. Dasar-Dasar Kebijakan Publik: Kajian Proses dan Analisa Kebijakan. Yogyakarta: Ombak.

Tahir, Arifin. 2011. Kebijakan Publik dan Transparansi Penyelenggaraan Pemerintahan 
Daerah. Jakarta: PT. Pustaka Indonesia Press

Winarno, Budi. 2012. Kebijakan

Publik Teori, Proses dan Studi

Kasus. Yogyakarta: CAPS

Wahab, Solichin Abdul. 2017. Analisis

Kebijakan, dari Formulasi ke

Penyusunan Model-Model

Implementasi Kebijakan Publik.

Jakarta: Bumi Aksara

Undang-Undang Republik Indonesia

Nomor 5 Tahun 1997 tentang

Narkotika, Psikotropika dan

Bahan Adiktif lainnya.

Undang-Undang Republik Indonesia

Nomor 22 Tahun 1997 tentang

Narkotika, Psikotropika dan

Bahan Adiktif lainnya.

Undang-Undang Republik Indonesia

Nomor 35 Tahun 2009 tentang

Narkotika.

Peraturan Presiden Republik Indonesia

Nomor 23 Tahun 2010 tentang

Badan Narkotika Nasional.

Peraturan Pemerintah Republik

Indonesia Nomor 40 Tahun

2013, tentang Pelaksanaan

Undang-Undang Nomor 35

Tahun 2009 tentang Narkotika.

Dokumen Badan Narkotika Nasional

(BNN) Kota Gorontalo 2018. 